\title{
A Study of Revitalization for Landscape Design at Oscar Hansen's Project Oś Słowackiego, Lublin
}

\author{
Shaikh M. Javeria \\ ERASMUS MUNDUS EMDiReB European Master in Diagnosis and Repair of Buildings Politechnika Lubelska, PhD scholar Hanyang \\ University, South Korea \\ *Corresponding Author: javeria@hanyang.ac.kr
}

Copyright (C) 2014 Horizon Research Publishing All rights reserved.

\begin{abstract}
In the first part of this research there is a thorough introduction of how Oscar Hansen, one of the recent prominent architect, whose composition towards free form is in continuation with that of Le Corbusier, 'Towards the new architecture'. He answers beautifully the growing needs of $21^{\text {st }}$ century world inhabitants. Now for Oscar Hansen the global world is one and to come up for an answer to this he travelled far and wide like how Le Corbusier did almost a century ago. His multidimensional approach towards architecture makes him universal; he opens all the physical and psychological boundaries and its barriers; and in a linear fashion takes all the architects and other professionals together towards the focused march of global accomplishment. The second part of research focuses on towards the revitalization of the project at the Słowacki estate, JuliuszSłowacki housing estate and Lublin Housing Cooperative, 1961. Here, the students are supposed to come up with the solution to revitalise the beautiful open form building housing complex.
\end{abstract}

Keywords Hansen, "The Continuous Linear System (LCD)" and "Continuous Form"

\section{Introduction}

Oskar Hansen (1922-2005)

Born in Helsinki, Finland, Oscar Hansen was a Polish architect, theorist, educator, painter, and sculptor. He studied at the Faculty of Mechanical Technology at the University of Vilnius (graduated 1942), he began studies in Lublin in the Department of Architecture in years 1948-50 and received the scholarship from the French government in Paris, where he practiced with Le Corbusier and met artists like Pablo Picasso. Here, he began his journey towards a form of the open ideas. Initially, Hansen was not able to implement the realities of the prevailing doctrine of socialist realism in his projects.

His teaching theories and especially Open Form theory had a huge influence on his students. In 2005, the retrospective exhibition "Towards the Open Form" ("Ku formieotwartej") developed this Open Form theory. Together with SveinHatløy and Zofia Hansen, he developed the concept of urban development of cities of the future "The Continuous Linear System (LCD)" and "Continuous Form".

The Continuous Linear System (LCD) originated in the late $60 \mathrm{~s}$ and the early $70 \mathrm{~s}$. The idea was to change the country in a specific way to eliminate the city and to build settlements in the four zones continuously from the sea to the mountains. These would all be reasonably organized. Equally, to each other there, would be the zones of human housing, nature, services and industry, which would have put a man on the one hand into contact with nature. And on the other hand, would allow him to live near to his work.

Hansen criticised the so-called centralised city as a linear solution for people living in the traditional European cities. These cities are a legacy of centuries of despotism, remainders after primitive towns, which can easily defend the enemy, but, at the same time, easy to control. Built around the centre, consisting of network of narrow streets, forced to live in the noise and crowds. The city according to him was a central prison of modern man. (Oskar Hansen, "Towards Open Form" 2005), Oskar Hansen died on May 11, 2005, after completion of this book. The influence of Alvar Alto's fan shaped buildings (as shown in Fig. 1) was evident from the fan shaped organized site planning.

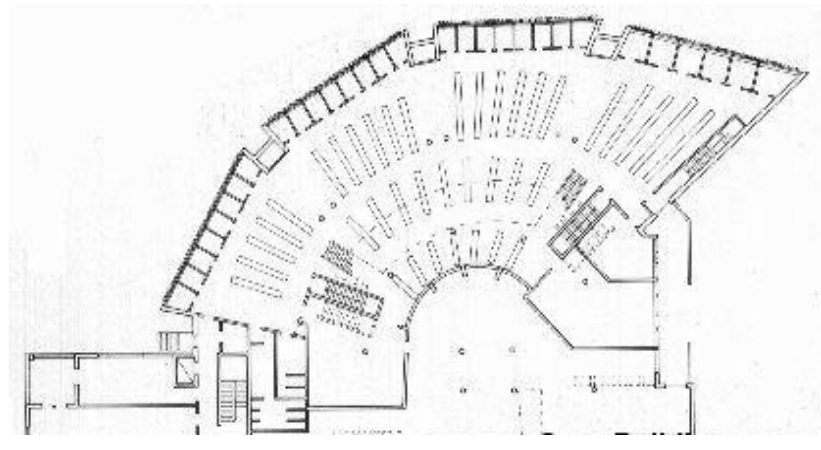

Figure 1. The mount angel Abbey Library Alvar Alto. (great building online)

The strategy devised here is to analyse and compare two 
town planning types, the old town of Lublin and the town planning done in 1960's by Oscar Hansen.

- Element of surprise

- Free form

- Labyrinth type walking

- Views and vistas

- Curved building form and pathways

- Non-continuous and non-monotonous facades

\section{Comparative Analysis of Old Town in Lublin with That of City Panning by Oscar Hansen,}

Figure 2 celebration of Views and vistas in the old town, playing with the sense of scale, from a narrow street to a sudden nice huge sculptural cathedral appearance. Below this phenomenon is visible from the panoramic view of the old town compared with that of the new planning.
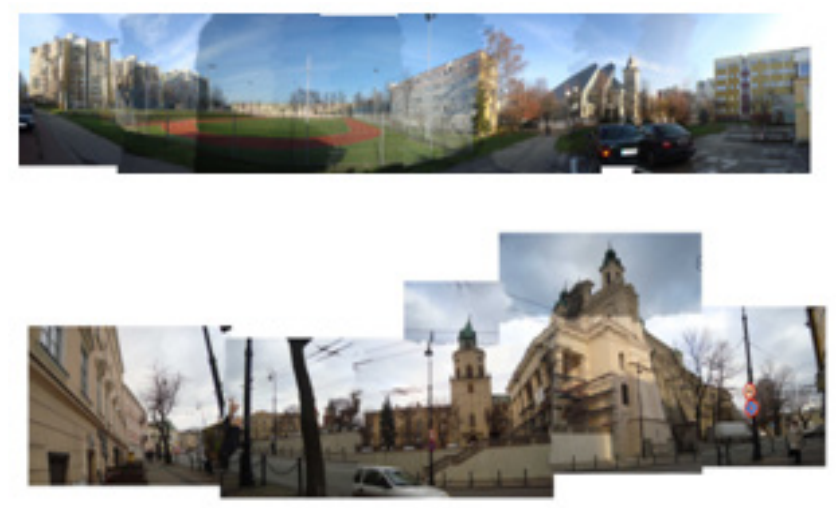

Figure 2. comparison of the panoramic view of both the new and the old town. (author 2009)

While analysing, the author immediately realised the relationship between the old town and the new one. It looked like opening up the old town, which is now more spacious and airy. The analogy here is similar to a flower maturing from a closed form opening towards the sun.

\subsection{The Form}

\section{Decentralization}

Hansen explanation of this idea in the book Towards Open Form was, organizing space on the basis of the Open Form that it is derived from the principle whereby events in motion are seen in relation to their environment. Architects and artists should not seek to create finite works. They should instead build systems and backgrounds that bring out and reflect the various occupants of the space. The people who occupy this environment should complement and develop these forms.

The term Open Form comes from the fact that the form awaits action on the part of the occupant; it is set up to be developed. In the Open Form organization of space, the objective (constant, specific) elements are so composed that the subjective elements, the evolutionary processes, comprise of the basic wealth and the nature of the form of man's environment.

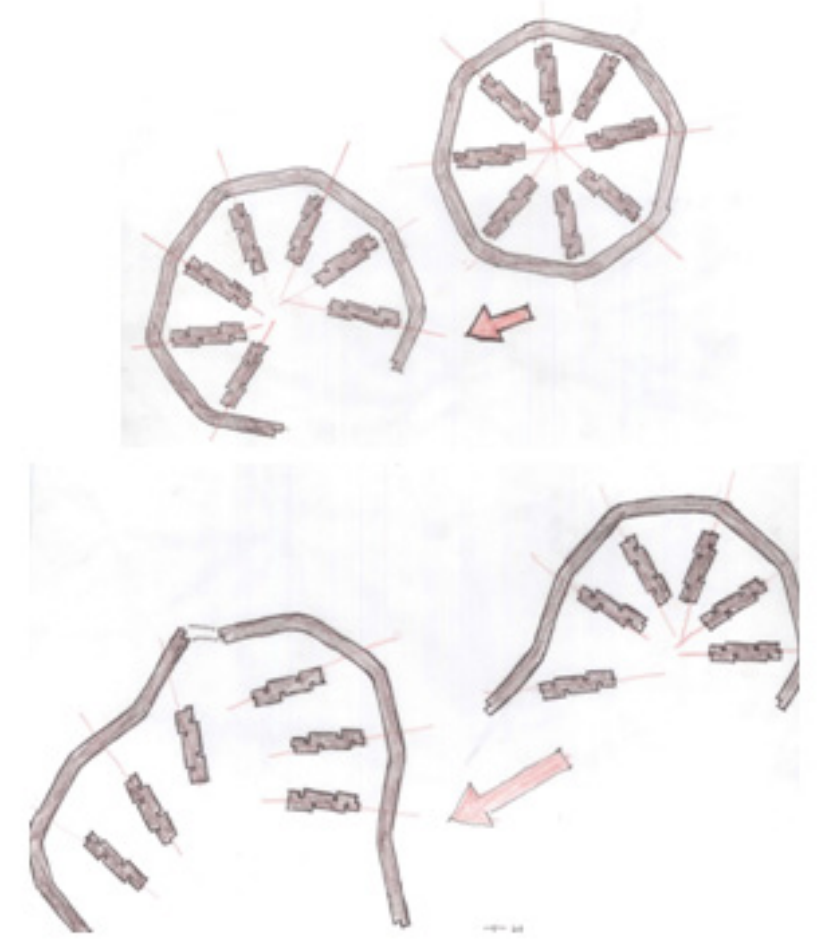

Figure 3. Transformation (author 2009)

In the previous figure 3 two it is clear how the form opens up from a central to multi central form. This phenomena is clear in the following diagram no four and five where in a very transparent way Hansen elaborate the concept of the opening of a city.

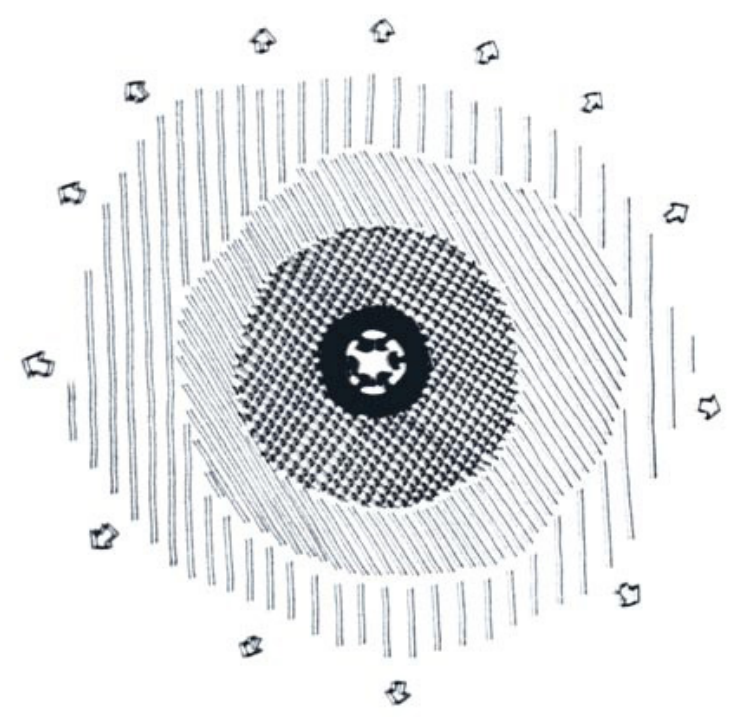

Figure 4. A City: Fixed centre-city diameter increasing the development of a large city is inadequate to its formal structure (Hansen towards open form) 


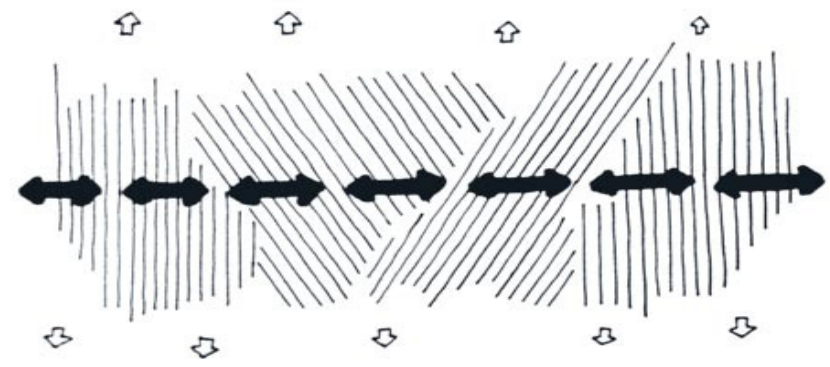

Figure 5. LCS: development of housing and service zones in any set relation (Hansen towards open form)

\subsection{The Model of a Linear Continuous System (LCS) Settlement Structure}

The Linear Continuous System is a method proposed for managing processes occurring in spatial-development systems in a planned economy - including a harmonious transition from the existing system to the new one - on the basis of a flexible, proportional co-dependence of alternating servicing and serviced zones.

The foregoing definition determined the objective elements of the system, which add up to a general division of space into cooperating zones. The subjective element will be the interpretation of these zones.

The LCS basically consists of three simultaneously developed zones:

- A housing-and-service zone with light industry, which is the primary serviced zone in this system;

- - A background for this housing service zone is a farming-and-forest zone with historical settlement systems and mining industry;

- - The third zone is heavy industry, located adjacent to the farming-and-forest zone.

These three basic zones are linked through safe transverse transit.

The guiding principle of LCS cross-section formation is zero-balance of employment, as well as "ecological equilibrium" of the environment. An additional parameter of the widths of the zones is a postulated 30-minute by walk to save the commuting time. The postulated zero-balance of the number of jobs and the working population in the cross section does not mean jobs have to be tied to domicile. Smooth transit along the system means that there is flexible choice of employment, while the zero-balance ensures the system's global equilibrium. [...](Towards Open Form 2005)

The above figure 6 shows typical town's plan that has anthropomorphic origin, visible during the urban analysis of the town's map. The long ways axis going to the residence is the town's spine, whereas the residence itself stands for the organism's head. The collegiate and academy play a role of human lungs, the great market square a stomach, and the side markets, kidneys. Corner bastions play a role of human limbs used for fighting. The concept of the man-town comes from the philosophy of the Italian Renaissance, which recognized a human being as the perfect work of nature.

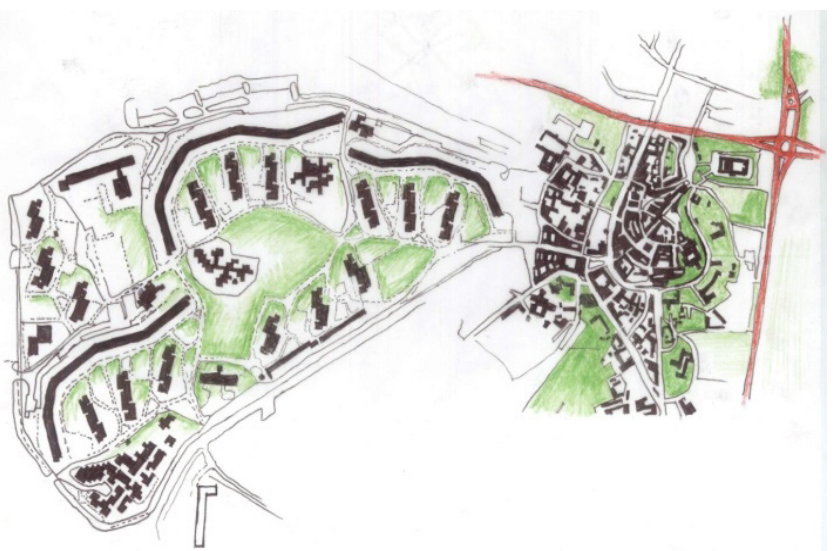

Figure 6. comparative analysis of the old town and the new. (author)

When comparing and re- considering the plan of Hansen, the site which is located in Lublin; there was a great connection and relationship between this new planning with the old. Some of the features will be discussed in detail. It is almost like the architect was opening the old plan and like a surgeon was very delicately and accurately conducting this task, having all the knowledge and the theories. It was a very subtle transaction from theory to practice of the Open Form.

In figure 6 the black which represent the built environment clearly shows the density was higher in the older town and in the new town the density decreases to a degree that the positive becomes negative and the negative becomes positive.
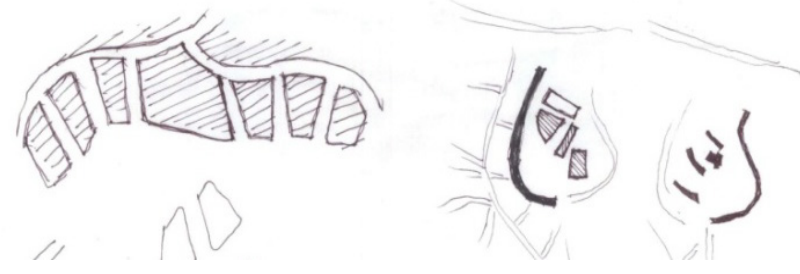

Figure 7. Study of the form (author 2009)

In figure 7 the study the forms are been analysed, where the author deliberately converts the positive spaces that is the built into negative for the new town by Hansen, and on the other hand, converts the negative spaces into positive for the old town to see the relationship; here is a clear connection between the negative and positive spaces. The old town looks like new when the conversion was reverse, and the same results were found when a similar action was applied to the new town. Hence, the new town looked like the old one when the built was replaced by the un-built. This is further evident from the figure 9and 10 below.

In the process of Revitalization of landscape design at Oscar Hansen's project OśSłowackiego, Lublin, a complete comparative analyses of the laws in Europe was carried out which were then applied on this project. The major point of conservation from the different Charts of conservation of Europe is analysed. 


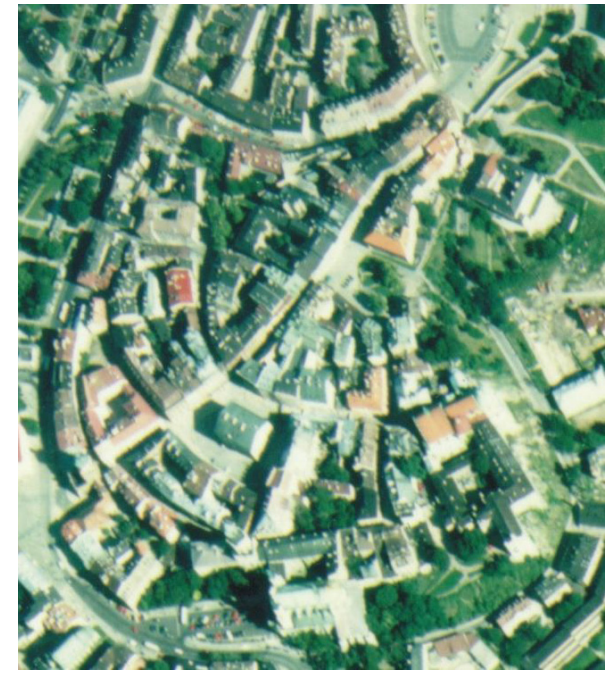

Figure 8. plan of the old town (Google satellite)

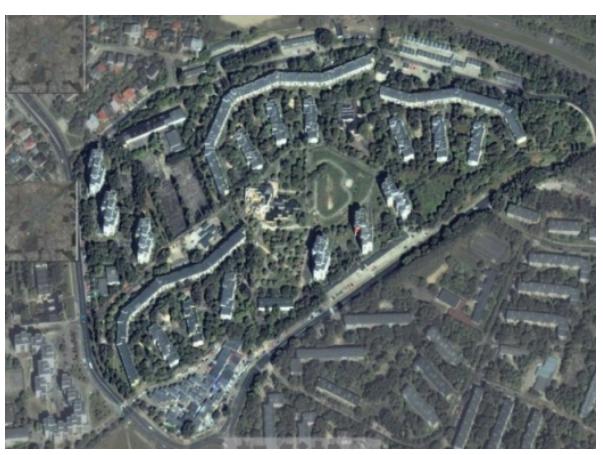

Figure 9. the Open Plan not very centralised but the curved building types are visible (Google satellite)
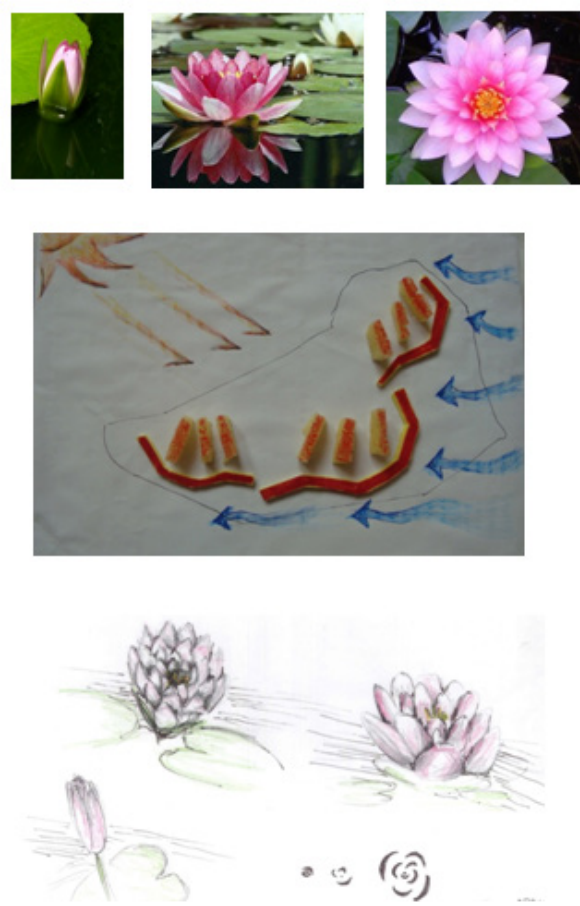

Figure10. An opening flower is represented (author 2009): Building opening up towards the sun with the force of the wind (author 2009)

\subsection{Problem in Process of Revitalization of Landscape Design at Oscar Hansen's Project OśStowackiego, Lublin}

In OśSłowackiego, Lublin urban areas, it is increasingly difficult to stop modern encroachments around monuments.

The executing agencies need authorization under the antiquity laws to demolish unauthorized structures which obstruct a clear view or mar the beauty of the monumental site.

There is a need to create a separate cell within the Department of maintenance and authority of OśSłowackiego,to pay special attention to the problems of this Heritage sites and to monitor the progress of preservation and management.

Since the new buildings of today will be the heritage of tomorrow, every effort must be made to ensure that contemporary architecture is of a high quality. (Page one congress on the European architectural heritage 21 - 25 October 1975

The Declaration of Amsterdam) Unless a new policy of protection and integrated conservation is urgently implemented, our society will shortly find itself obliged to give up the heritage of buildings and sites which form its traditional environment. (Page three Congress on the European architectural heritage 21 - 25 October 1975 The Declaration of Amsterdam)

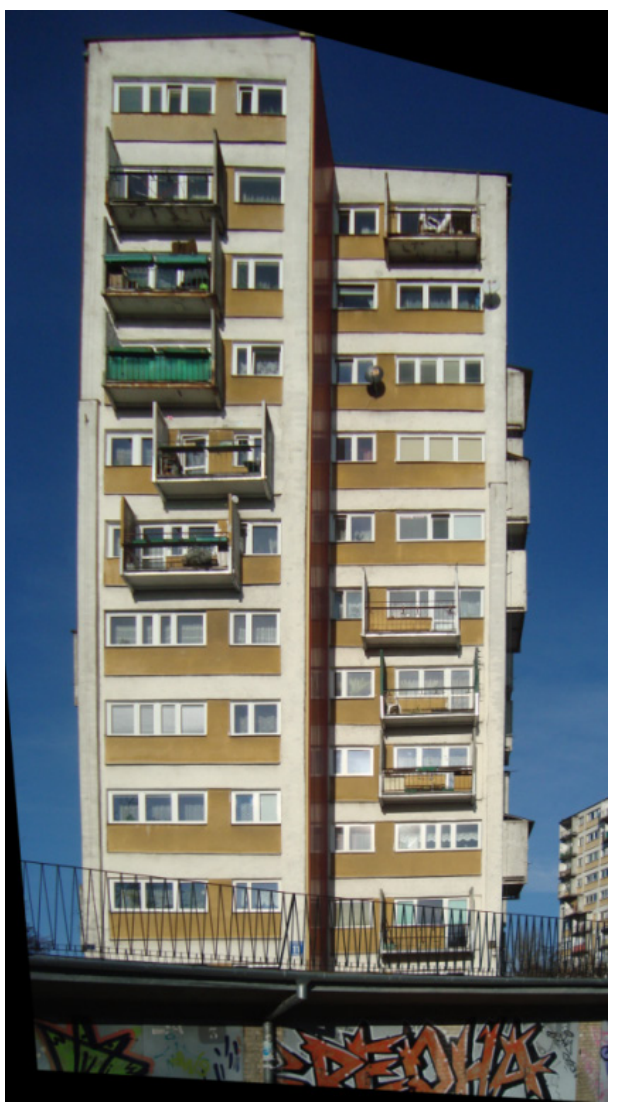

Figure 11. elevation of the old town (author 2009)

Comparative analysis of the elevations comparative 
analysis, of the new town and the old, in the figure 13 Hansen's design above of non-monotonous elevation detail has been shown where he creates a harmonised play in balcony design. Similar to that of the elevation detail in the old facade, here too the windows are designed in this non-monotonous fashion.

Integrated conservation averts these dangers.

Integrated conservation is achieved by the application of sensitive restoration techniques and the correct choice of appropriate functions. It should be noted that integrated conservation does not rule out the introduction of modern architecture into areas containing old buildings provided that the existing context, proportions, forms, sizes and scale are fully respected and traditional materials are used. (Page 3 European Charter of the Architectural Heritage Adopted by the Council of Europe, October 1975)

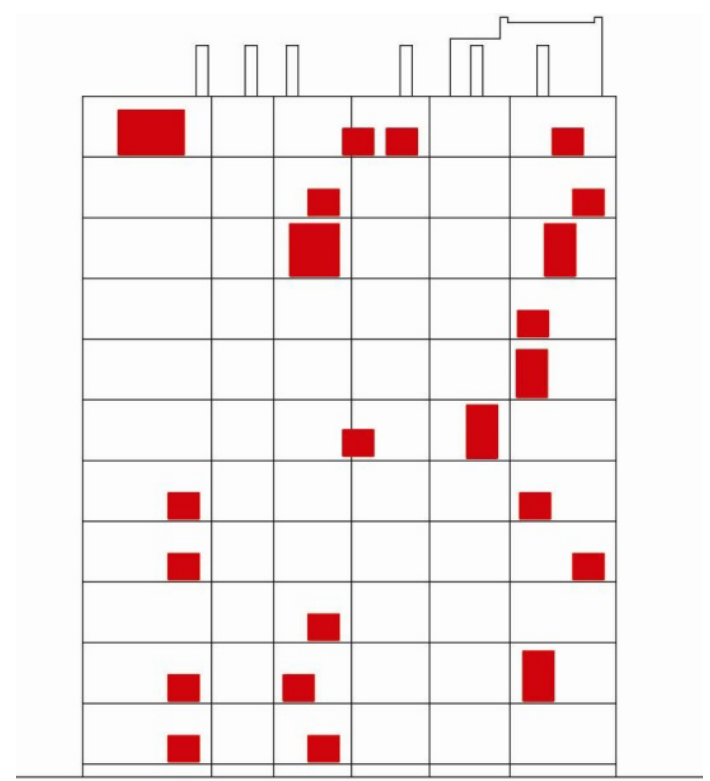

Figure12. elevation (politechnikalubeleska students2009)

The non-continuous and unparallel placement of the balconies enhances Hansen's concept of decentralization further more three dimensionally.

\section{The Revitalization Design}

The designing process started with the quest of geometrical harmony; hence, a series of grids were constructed to find the missing clues of Hansen's design. On the basis of the analysis it was proved that the first buildings from the tripartite organization were uni-directional, and the seconds building were parallel as well.

\subsection{Design Strategy}

Landscape revitalization has been chosen by the author as a design strategy. The reason being is that there is an abundance of space for cultivation of plants, being an open plan. Secondly since there was a liberty of cultivation of plants of any kind by the dwellers and as it was an open plan, hence over time it lost the sense of geometry. Therefore there is a need of planning and organization in the landscape, hence the research starts from the concept of landscape in Europe and then it will focus on the concept of Hansen.

Believing that the landscape is a key element of an individual's and social well-being and the protection, management and planning of landscape entail rights and responsibilities for everyone. It is important to achieve sustainable development based on a balanced and harmonious relationship between social needs, economic activity and the environment;

Noting that the landscape has an important public interest role in the cultural, ecological, environmental and social fields and that it constitutes a resource favourable to economic activity and whose protection, management and planning can contribute to job creation;

Aware that the landscape contributes to the formation of local cultures and that it is a basic component of the European natural and cultural heritage, contributing to human well-being and consolidation of the European identity (European Landscape Convention Florence, 20.X.2000)
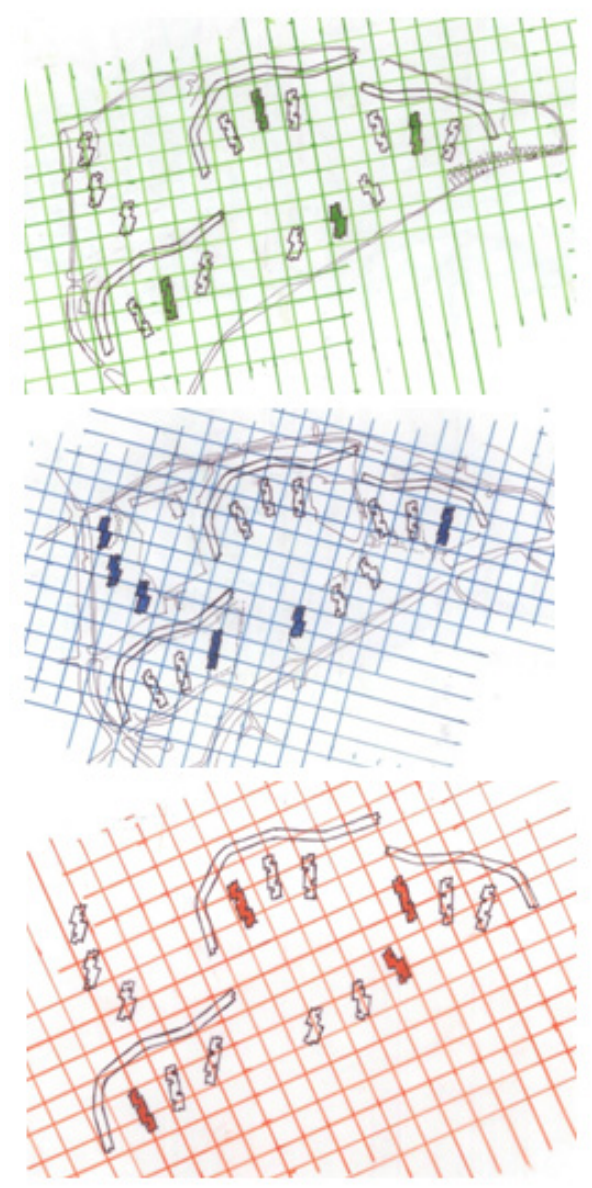

Figure 13. construction of the grids (author 2009)

Acknowledging that the landscape is an important part of the quality of life for people everywhere: in urban areas and 
in the countryside, in degraded areas as well as in areas of high quality, in areas recognised as being of outstanding beauty as well as everyday areas;

In this figure 13 the author of this paper attempts to find out the rationale of the geometry behind the planning.

In the figure 14 the author noted three points which were originally united, but with time, they multiplied and the distance increased. So, these points are marked and celebrated for the revitalization of landscape.

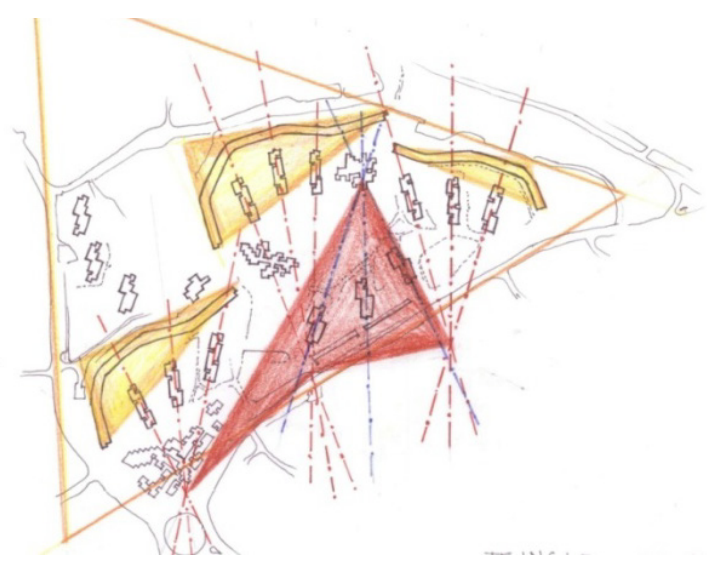

Figure 14. tripartite organization (author 2009) in quest for the geometry (author 2009)

The landscape became a background in an Open Form convention with a special location of the trees and grass, in which nature, man, architecture, and art represented a balanced whole. This experience proves that it is possible to adapt the past - to extend its moral age, make it more contemporary, by giving a new insight into traditional arrangements, instead of moving or destroying it. (Hansen 2004)

\section{Recommendations}

1. At national level: Sub-national level institutions should be set up in Lublin. At regional level: There should be coordination and interaction between such institutions at.

2. Trained professionals will make qualitative difference in Revitalization of Oscar Hansen's project OśSłowackiego, Lublin.

3. Easy Accessibility to the researchers, scholars and to some extent students at higher level, and to have access to the Heritage preservation materialof Oscar Hansen's project OśSłowackiego, this should be present at Maintenance Department on the site.

\section{Conclusion}

This paper basically deals with the issue of reversible conservation. A design approach which is continuous from that of Hansen, which fulfils communal needs of the inhabitants of the area's and a design that can satisfy the emotional feelings of the occupants by two ways. Firstly, by the aesthetics i.e. the tangible aspects, and secondly, by the monetary compensation i.e. the economical, healthy and affordable addition to the neighbourhood of the residential area of project OśSłowackiego, Lublin.

All the five chapters of the book revolve around the core theme of revitalization, which is discussed here as a viable alternative of reversibility, continuity, and healthy living. The beauty of this solution is its flexibility. Not only this solution provides parallel communal activities for the present dwellers but also this is considered to be essential for preserving the Oscar Hansen's designfor the future generations.

The concept of Revitalization is explained well in book statement, i.e. "The act of reviving or condition of being revived: reactivation, rebirth, renewal",

This research has proved the above statement through various comparisons provided in detail in different chapters. To strengthen this idea the dissertation was primarily focused upon the residential sector in Lublin. There are three different examples discusses individually. The old town and the analogy with the flower, one of town is closed other was open. However, this interpretation was truly an analysis by the author this dissertation. This idea is not the new one, and the three case studies from three different parts of Lublin are explained at length to support this argument.

The paper has provided in detail the Revitalization proposal for which creative design decisions are discussed in detail namely, selection of material, comfort levels, space utilization, and site development; according to the sun path diagrams. This Revitalization is based on precedent conducted studies. It is supposed to be within the communal needs by the use of spaces providing sheltered walkways and small activities where measures were taken to control the range of the temperature.

Furthermore, the Revitalization proposal discusses following main characteristics:

- Addition should allow occupants to control their environment by having opening temporary and adjustable shades to keepsnow out of the walk ways.

- Where possible occupants should feel free to adjust clothing, move to more comfortable places, and so on.

- Environment should be within usual comfort limits by use of shading.

- Good Revitalization will provide

- Appropriate indoor conditions

- Possibilities for adjustment

- Freedom to adapt

Although there are certain limitations of this revitalization project, yet on the average it is the most suitable option that the architects of today should pay attention towards while designing the conservation. The concept will even further be explored in future studies by the author and the invitation is open to all the architecture students to discuss and debate this 
subject.

\section{REFERENCES}

[1] Oskar Hansen "Ku formieotwartej", red. JolaGola, układgraficzny Oskar Hansen, FundacjaGaleriiFoksal (Warszawa), Revolver (Frankfurt), we współpracy z Muzeum ASP w Warszawie, 2005. review: [1]

[2] Oskar Hansen, "Towards Open Form / Ku FormieOtwartej". Frankfurt am Main: Revolver, 2005. Paperback 256 pages / ISBN 83-89302-07-1. reviews: [2], [3]. The non-textual introduction is an iteration from the Polish catalogue for the 1960 Milan Triennal. 'Bridging' the book's two parts are interviews with the artist: Joanna Mytkowska's in the first part (conducted in spring 2003), and fragments ofHans Ulrich Obrist's in the second. Oskar Hansen died on May 11, 2005, after work on this book had been completed and it had been sent to press. The book has been left unchanged.'

[3] Obieg, Forma Otwartajako passe-partout patriarchatu? PawilonStabilnejFormy (CezaryKlimaszewski, Tomasz
Kozak, Tomasz Malec)[4]

[4] "OSKAR HANSEN'S MUSEUM OF MODERN ART" exhibition, Berlin 2008

[5] European Landscape Convention, Florence, 20.X.2000, Explanatory ReportHeritage and Landscape - Website

[6] Polytechnic University Lublin, Department of Architecture 2009 students work

[7] Bernardo Morando. (2009). In EncyclopædiaBritannica. Retrieved November 11, 2009, from Encyclopædia Britannica Online:

[8] http://www.britannica.com/EBchecked/topic/391854/Bernar do-Morando

[9] man - town illustration from a work by francesco martini "traktato di architetturacivile e militare"

[10] http://www.fondazione-delbianco.org/inglese/relaz/toA3.htm

[11] UNESCO official website 